\title{
Interaction Of Brand And Taste In The Liking Of Cola Drinks By School Children
}

\author{
Hanna Bartneck, Christoph Bartneck \\ University of Canterbury, HIT Lab NZ \\ Private Bag 4800, 8140 Christchurch \\ New Zealand \\ christoph.bartneck@canterbury.ac.nz
}

\begin{abstract}
Sugar sweetened soft drinks play an important role in obesity and world wide brands, such as Coca Cola, spend considerable resources on branding and advertising. As a result, their soft drinks tend to be up to 2.5 times more expensive than store brand cola drinks. We investigated the effect that the taste and the label has on the liking of cola drinks by school children. Taste did not have any significant effect and there was a significant interaction effect between the label and the taste. The children preferred cola drinks with their correct labels. A familiar brand with a familiar taste is liked more and the Coca-Cola company with its large advertising campaign and market share take advantage of this effect.
\end{abstract}

Keywords: cola, liking, branding, label, children

\section{Introduction}

The consumption of sugar-sweetened drinks, such as Cola drinks or energy drinks, are associated with childhood obesity Ludwig et al., 2001. The children's liking of soft drinks and the consumption of their parents play a major role in their own consumption Grimm et al., 2004. Eagle et al. 2004 indicated that "advertisement present a problem in relation to food selection choice" but also acknowledged that other factors, such as peer pressure and in-school food services contribute to the problem. Skaczkowski et al. [2016] performed a meta review and concluded that packaging does have an influence on the experience of unhealthy food and drinks. They called this influence "sensation transfer".

Brands play an important role in our economy and Coca Cola is the largest brand in the market in New Zealand according to a Euromonitor report 1 . The Coca Cola company produces many drinks, but Cola drinks have the largest

1 http://www . euromonitor. com/soft-drinks-in-new-zealand/report 
market share in New Zealand 2 There is a considerable discussion in New Zealand to introduce a special sugar tax for sugar-sweetened drinks Mann. 2017, in particular since first research results indicate that such a tax has a reduces their consumption Silver et al. 2017.

Studies on the perception of brands and tastes date back to 1948 when Pronko and Bowles Jr 1948 conducted studies to investigate if participants would be able to distinguish different Cola drinks. More recently, Breneiser and Allen 2011 conducted a blind taste experiment in which participants were either show the Cola brand they were drinking or had to taste them without any brand information. Their results showed that participants ranked the Coco-Cola brand in $50 \%$ of the cases as their first choice in the non-blind condition but only in $31 \%$ of the cases in the blind condition. The problem with their study is that the availability of brand information, the brand itself and the taste are not completely independent from each other. The participants were not confronted with conflicting information, such as the taste of a store brand cola presented in a Coca-Cola bottle and vice versa. We were therefore interested if the sensation transfer occurs when the Label and the Brand were completely manipulated.

In addition we noticed while visiting a local supermarket that the prices for Cola drinks don not only vary dramatically across brands but even within brands. Our price comparison (see Table 1) shows that Coca Cola is around 2.5 times more expensive than the house brand (Nice Cola). Even worse, at the checkout counter a 0.6 litre bottle of Coca Cola was offered for $\$ 4.15$, which is even more expensive than the 2.25 litre bottle of Coca Cola for $\$ 3.99$. The question is if Coca Cola really tastes two and half times better than the store brand cola.

\begin{tabular}{lrrr}
\hline Name & liters & price & $\$$ per l \\
\hline Coca Cola & 2.25 & $\$ 3.99$ & $\$ 1.77$ \\
Pepsi & 2.00 & $\$ 2.00$ & $\$ 1.00$ \\
Nice Cola & 1.25 & $\$ 0.89$ & $\$ 0.71$ \\
\hline
\end{tabular}

Table 1: Prices of Cola drinks in New Zealand dollars

\section{Method}

We conducted a 2 (Taste) x 2 (Label) mixed within/between experiment in which Taste is the within participant factor (Coca Cola \& Store Brand) and the Label is the between participant factor (Coca Cola \& Store Brand).

\section{$2.1 \quad$ Measurements}

The age, gender and the liking of the drink was reported on a paper questionnaire. The liking of each drink was measured on a seven point Likert scale.

\footnotetext{
2 https://www.statista.com/statistics/422491/new-zealand-market-share-of-soft-drinks-by-categor
} 


\section{$2.2 \quad$ Participants}

53 children aged between 10-12 $(m=11.14$, StdDev $=0.411)$ participated in the study. 30 were female and 23 male. They were all students from the Cobham Intermediate School, Christchurch, New Zealand.

\subsection{Materials}

We purchased several bottles of Coca Cola and a Store Brand Cola (Nice Cola) (see Figure 1). Coca-Cola contained 10.6gr of sugar per $100 \mathrm{ml}$ while Nice Cola contained 7.6gr. Other ingredients, such as acids, may balance the perceived sweetness but no information about their amount in the drinks was available.

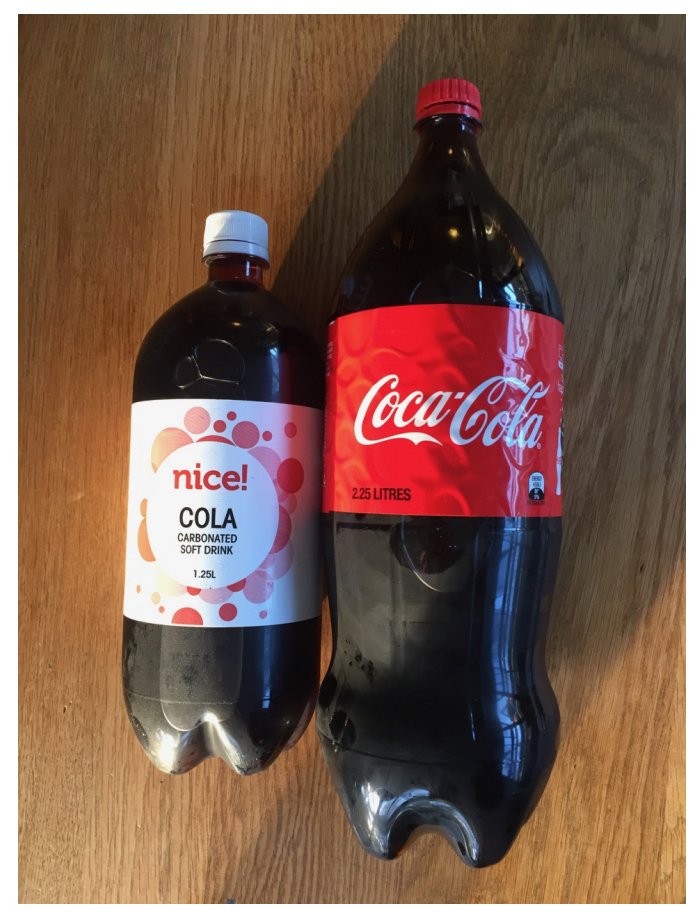

Figure 1: Store Brand Cola (left) and Coca-Cola (right)

For half of the bottles we swapped their content with the other brand. In total we had four bottles:

- A Coca-Cola bottle with Coca-Cola content (A)

- A Coca-Cola bottle with Store Brand Cola content (B)

- A Store Brand Cola bottle with Coca-Cola content (C)

- A Store Brand Cola bottle with Store Brand Cola content (D) 
We secretly labelled the bottles to be able to pick the correct bottles for each participant. The temperature of the drink might have an influence on its perceived sweetness and hence its liking Bartoshuk et al. 1982. We therefore stored all the bottles in a cooler box.

\subsection{Process}

The participants were welcomed and then asked to fill in a short demographic questionnaire. Afterwards the participants were offered their first sample drink $(30 \mathrm{ml})$. We used three measuring cups that were marked at $30 \mathrm{ml}$ to be able to measure the same amount of cola for each sample. Each of the measuring cups was used for only one of the three drinks to avoid any kind of mixing of the drinks.

We counterbalanced the order in which the participants tasted the two samples. A quarter of them would first taste $\mathrm{A}$ and then $\mathrm{B}$ and a second quarter first B and then A. The same pattern applied to C and D.

After drinking the first sample the participants were asked to rate their liking of the drink. Next, the participants were asked to drink some water to clear any residual taste. We then offered them a second sample which they were again asked to rate. After the experiment we thanked the participants for their contribution. The participants did not receive any financial incentives.

\section{$3 \quad$ Results}

We performed a Repeated Measure Analysis of Variance (ANOVA) in which the Label was the within factor (Coca Cola or Store Brand) and the Taste was the between factor (Coca Cola or Store Brand). The means for each condition are shown in Figure 2. The Label had a significant effect on Liking $(F(1,50)=$ 4.096, $p=0.049)$. Participants liked the drink with the Coca Cola label $(m=$ $5.13)$ more than the drink with the house brand label $(m=4.62)$. Taste had no significant effect on Liking and there was no interaction effect between Taste and Label.

We performed a second ANOVA in which we only considered the ratings for the first drink each participant rated. This turns the experiment into a complete between participants setup. The means for each condition are shown in Figure 3. There was no main effect for Taste or Label. There was a significant interaction effect between Taste and Label $(F(1,47)=4.229, p=0.045)$.

We continued with only considered the first drinks and a t-Test revealed that there was no significant influence of Gender on liking $(t(49)=-0.897, p=$ 0.374). There was, however, a significant Pearson correlation between age and Liking $(r=-0.262, p=0.030)$. Younger children liked the drinks more than older. 


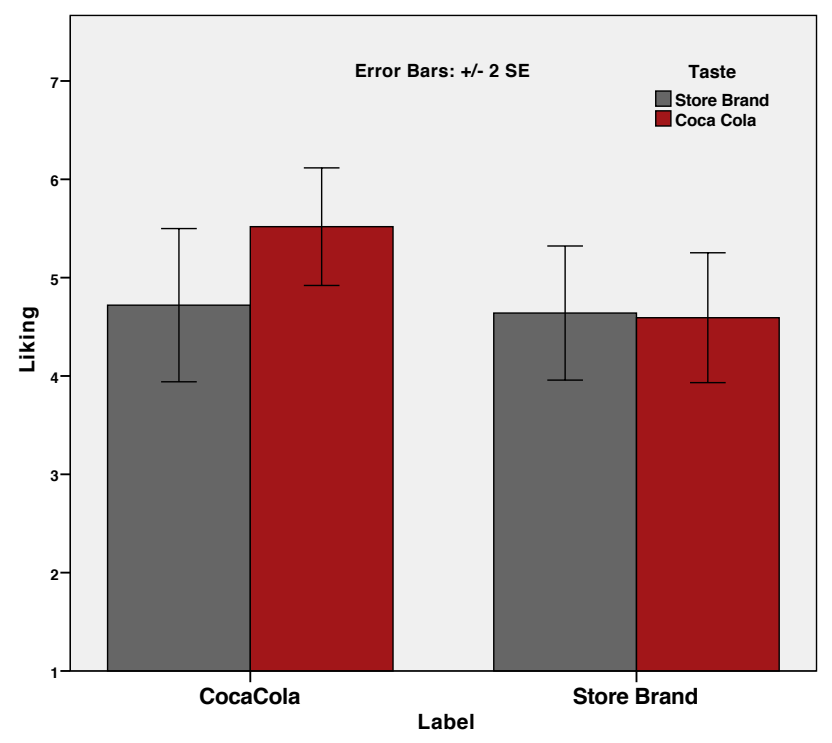

Figure 2: Mean rating of drinks

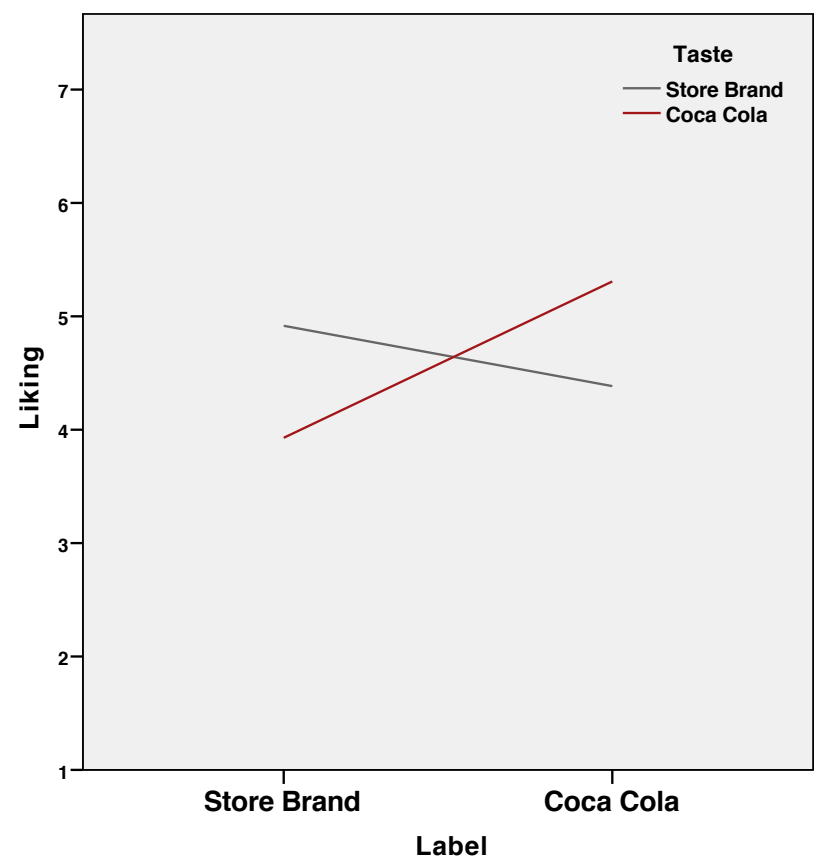

Figure 3: Mean liking ratings for the first drink 


\section{Conclusion}

Our results show that that the Liking of a Cola drink depends on both, the Label and the Taste together. The second Analysis of Variance showed a strong interaction effect between Label and Taste. When we consider the experiment with a within Label factor it becomes clear that only the Label had a significant main effect.

When we consider only the first drink the participants consumed and thereby reducing the experiment to a complete between participants setup then we observe an interaction effect between Taste and Label. Both, Coca-Cola and Store Brand Cola are more liked with their correct Labels compared to them being presented with incorrect labels. This interaction effect could possibly be explained by the incongruent information presented which may lead to a cognitive dissonance. The participants might have subconsciously noticed that the taste and the label do not match and hence have rated the drink lower.

In both analyses, the Taste did not significantly influence the Liking ratings. Only the Label had a significant influence in the first analysis. The success of Coca-Cola is therefore not based on its taste, but on its omniscient marketing campaigns and their large market share. Many customers are familiar with the product and this familiarity makes the product more likeable. Consumers know what to expect and are satisfied if their expectations are met. In any case, the Coca-Cola did most certainly not taste two and half times better than store brand cola and hence it can be concluded that customers pay for the label, not the taste.

\section{References}

L. M. Bartoshuk, K. Rennert, J. Rodin, and J. C. Stevens. Effects of temperature on the perceived sweetness of sucrose. Physiology \& Behavior, 28(5):905910, 1982. ISSN 0031-9384. doi: 10.1016/0031-9384(82)90212-8. URL http: //wWw.sciencedirect.com/science/article/pii/0031938482902128.

Jennifer E. Breneiser and Sarah N. Allen. Taste preference for brand name versus store brand sodas. North American Journal of Psychology, 13(2):281290, 2011. ISSN 1527-7143.

Lynne Eagle, Sandy Bulmer, Anne De Bruin, and Philip J. Kitchen. Exploring the link between obesity and advertising in new zealand. Journal of Marketing Communications, 10(1):49-67, 2004. ISSN 1352-7266. doi: 10.1080/1352726042000207199. URL http://dx.doi.org/10.1080/ 1352726042000207199 .

Gebra Cuyun Grimm, Lisa Harnack, and Mary Story. Factors associated with soft drink consumption in school-aged children. Journal of the American Dietetic Association, 104(8):1244-1249, 2004. ISSN 0002-8223. doi: 10. 1016/j.jada.2004.05.206. URL http://www.sciencedirect.com/science/ article/pii/S0002822304009095. 
David S. Ludwig, Karen E. Peterson, and Steven L. Gortmaker. Relation between consumption of sugar-sweetened drinks and childhood obesity: a prospective, observational analysis. The Lancet, 357(9255):505-508, 2001. ISSN 0140-6736. doi: 10.1016/S0140-6736(00)04041-1. URL http://www. sciencedirect.com/science/article/pii/S0140673600040411.

Britt Mann. The case for and against a sugar tax in new zealand. The Press, 2017. URL http://www.stuff.co.nz/life-style/well-good/teach-me/ 89926905/The-case-for-and-against-a-sugar-tax-in-New-Zealand.

N. H. Pronko and J. W. Bowles Jr. Identification of cola beverages. i. first study. Journal of Applied Psychology, 32(3):304-312, 1948. ISSN 0021-9010. doi: $10.1037 / \mathrm{h} 0054425$.

Lynn D. Silver, Shu Wen Ng, Suzanne Ryan-Ibarra, Lindsey Smith Taillie, Marta Induni, Donna R. Miles, Jennifer M. Poti, and Barry M. Popkin. Changes in prices, sales, consumer spending, and beverage consumption one year after a tax on sugar-sweetened beverages in berkeley, california, us: A before-and-after study. PLOS Medicine, 14(4):e1002283, 2017. doi: 10.1371/journal.pmed.1002283. URL https://doi.org/10.1371/journal. pmed.1002283.

Gemma Skaczkowski, Sarah Durkin, Yoshihisa Kashima, and Melanie Wakefield. The effect of packaging, branding and labeling on the experience of unhealthy food and drink: A review. Appetite, 99(April 2016):219-234, 2016. ISSN 01956663. doi: 10.1016/j.appet.2016.01.022. URL http://www.sciencedirect. com/science/article/pii/S0195666316300216. 